\title{
Protective Effect of Aqueous Crude Extract of Neem (Azadirachta indica) Leaves on Plasmodium berghei-Induced Renal Damage in Mice
}

\author{
Voravuth Somsak, Sukanya Chachiyo, Ubonwan Jaihan, and Somrudee Nakinchat \\ Department of Clinical Chemistry, Faculty of Medical Technology, Western University, Kanchanaburi 71170, Thailand \\ Correspondence should be addressed to Voravuth Somsak; voravuthsomsak@gmail.com
}

Received 14 June 2015; Revised 14 August 2015; Accepted 18 August 2015

Academic Editor: Shyam Sundar

Copyright (C) 2015 Voravuth Somsak et al. This is an open access article distributed under the Creative Commons Attribution License, which permits unrestricted use, distribution, and reproduction in any medium, provided the original work is properly cited.

\begin{abstract}
Malaria is a major public health problem in the world because it can cause of death in patients. Malaria-associated renal injury is associated with $45 \%$ of mortality in adult patients hospitalized with severe form of the disease. Therefore, new plant extracts to protect against renal injury induced by malaria infection are urgently needed. In this study, we investigated the protective effect of aqueous crude extract of Azadirachta indica (neem) leaves on renal injury induced by Plasmodium berghei ANKA infection in mice. ICR mice were injected intraperitoneally with $1 \times 10^{7}$ parasitized erythrocytes of PbANKA, and neem extracts (500, 1,000 , and $2,000 \mathrm{mg} / \mathrm{kg}$ ) were given orally for 4 consecutive days. Plasma blood urea nitrogen (BUN) and creatinine levels were subsequently measured. Malaria-induced renal injury was evidenced as marked increases of BUN and creatinine levels. However, the oral administration of neem leaf extract to PbANKA infected mice for 4 days brought back BUN and creatinine levels to near normalcy, and the highest activity was observed at doses of 1,000 and 2,000 mg/kg. Additionally, no toxic effects were found in normal mice treated with this extract. Hence, neem leaf extract can be considered a potential candidate for protection against renal injury induced by malaria.
\end{abstract}

\section{Introduction}

Malaria caused by Plasmodium parasites is a major public health problem in tropical zones including Africa, South and Central America, and Asia, where it is most prevalent, with estimates of 216 million cases and 655,000 deaths. More than $85 \%$ of malaria cases and $90 \%$ of malaria deaths occur in sub-Saharan Africa, mainly in young children [1]. Causes of death in malaria have been reported including cerebral malaria, acute hemolysis and severe anemia, and vital organ damage and failure [2]. For organ damage, malaria-associated renal injury occurs in between 1 and $4 \%$ of hospitalized patients with a mortality that can reach up to $45 \%$ [3]. The pathogenesis of malaria-associated renal injury is multifactorial and not well characterized, but several hypotheses suggest involvement of cytoadherence of parasitized erythrocytes. Recent studies suggest that proinflammatory response, oxidative injury, and apoptosis probably explain part of this injury $[4,5]$. During malaria infection, it causes generation of reactive oxygen species (ROS), such as superoxide anion and hydroxyl radical which deplete glutathione levels and inhibit the activity of antioxidant enzymes, especially in renal tissues $[6,7]$. Therefore, oxidative stress induced by malaria infection may produce cellular injury and necrosis via several mechanisms including peroxidation of membrane lipids, protein denaturation, and DNA damage [8].

In this respect, medicinal plants are potential targets for research and development of alternative drugs. In particular, Azadirachta indica (neem) is one of the most promising medicinal plants, having several biological activities, especially as antioxidant, anti-inflammatory, antibacterial, antifungal, and antiulcer ones [9-12]. Several studies have been undertaken on the protective effects of neem [13-15]. It has been described that aqueous crude extract of neem leaves showed significant hypoglycemic, hypolipemic, hepatoprotective, and hypertensive activities [16-19]. Moreover, protective effect on diabetic nephropathy in rats of neem leaf extract has also been reported [20]. However, the protective 
effect of neem extract on renal damage induced by malaria infection has not yet been reported. Hence, the aim of the present study was to evaluate the possible protective effect of aqueous crude extract of neem leaves on $P$. berghei-induced renal damage in mice.

\section{Materials and Methods}

2.1. Crude Extract Preparation. The neem leaves were collected from Kanchanaburi province, Thailand. The plants were identified in the Faculty of Pharmacy, Payap University. The leaves were cleaned and dried using hot air oven at $55^{\circ} \mathrm{C}$ for $6 \mathrm{~h}$ and then they were powdered. The powder was used for the preparation of aqueous crude extract according to the procedure previously described with some modification [10]. The dried powders of neem leaves were boiled with distilled water (plant: water $=1: 20, \mathrm{w} / \mathrm{v}$ ) for $6 \mathrm{~h}$ and then filtered. The filtrate was evaporated to dryness in a vacuum evaporator to yield the aqueous crude extract of neem leaf. Before experiment, the neem leaf extract was dissolved in $20 \%$ Tween- 80 at the doses of 500, 1,000, and 2,000 mg/kg.

2.2. Mice. Female ICR mice obtained from the National Laboratory Animal Center, Mahidol University, Thailand, 46 weeks old, weighing 25 to $30 \mathrm{~g}$ were used for the study. They were given clean tap water and pelleted diet ad libitum. All mouse procedures were approved by the Ethical Committee on Animal Experimentation, Faculty of Medical Technology, Western University, Thailand.

2.3. Parasite Strain and Infection of Animals. Plasmodium berghei ANKA (PbANKA) obtained from Dr. Chairat Uthaipibull from BIOTEC, NSTDA, Thailand, was used. Naïve ICR mice were inoculated with $1 \times 10^{7}$ parasitized erythrocytes of PbANKA by intraperitoneal (IP) injection. Parasitemia was daily monitored by microscopy of Giemsa stained thin blood smear. Additionally, renal markers including BUN and creatinine levels were also measured.

2.4. Measurements of Renal Markers. For determination of renal damage, BUN and creatinine levels were used as markers in this study. Blood was collected from tail vein of mice into heparinized hematocrit tubes. Centrifugation was then performed with $10,000 \mathrm{~g}$ for $10 \mathrm{~min}$. Next, plasma was collected into a new $1.5-\mathrm{mL}$ tube for measurement of BUN and creatinine using commercially available diagnostic kits (BioSystems S. A. Costa Brava, Barcelona, Spain) according to the manufacturer's instructions.

2.5. Efficacy Test In Vivo. The standard 4-day suppressive test against PbANKA infection in mice was employed [21]. Groups of naïve ICR mice (5 mice of each) were inoculated with $1 \times 10^{7}$ parasitized erythrocytes of PbANKA by IP injection. They were subsequently treated with 500, 1,000, and $2,000 \mathrm{mg} / \mathrm{kg}$ of neem leaf extract orally by gavage twice a day for 4 consecutive days. Normal mice treated with or without $2,000 \mathrm{mg} / \mathrm{kg}$ of extract were used as healthy controls, while PbANKA infected mice treated with 20\% Tween- 80 were used as disease controls. On day 5 of experiment, blood was collected for measurement of BUN and creatinine levels.

2.6. Statistical Analysis. The one-way ANOVA was used to analyze and compare the results at a 95\% confidence level. Values of $P<0.05$ were considered significant. Results were expressed as mean \pm standard error of mean (SEM).

\section{Results}

3.1. Renal Damage Induced by Plasmodium berghei Infection in Mice. ICR mice were infected with $1 \times 10^{7}$ parasitized erythrocytes of PbANKA by IP injection; parasitemia and renal markers were then daily monitored. It was found that PbANKA was firstly detectable on day 2 after infection with a parasitemia less than $1 \%$ and reached $>60 \%$ on day 12 (Figure 1(a)). Moreover, during blood stage propagation of PbANKA in mice, BUN and creatinine levels were markedly increased in the response to the presence of the parasite, which reached significant values firstly on day 4 after infection (Figures 1(b) and 1(c)). The infected mice died within 2 weeks (Figure 1(d)).

\subsection{Protective Effect of Neem Leaf Extract on Renal Dam-} age Induced by Plasmodium berghei Infection in Mice. ICR mice were infected with $1 \times 10^{7}$ parasitized erythrocytes of $\mathrm{PbANKA}$ by IP injection and given 500, 1,000, and $2,000 \mathrm{mg} / \mathrm{kg}$ of the neem leaf extract for 4 consecutive days subsequently with measurement of renal markers. As showed in Figures 2(a) and 2(b), during PbANKA infection, renal damage was developed as indicated by increasing of BUN and creatinine levels significantly $(P<0.01)$. Interestingly, neem leas extract exerted a dose-dependent protection of renal damage induced by PbANKA infection as indicated by reduction of BUN and creatinine levels in the extract treated groups. Significant $(P<0.05)$ protections were observed at doses of 1,000 and $2,000 \mathrm{mg} / \mathrm{kg}$ of neem leaf extracts, compared with untreated groups, and no significances were found when compared to normal groups. Moreover, prolonged survival time was also observed in infected mice treated with 1,000 and 2,000 mg/kg of the extracts (25 days for $1,000 \mathrm{mg} / \mathrm{kg}$ and 30 days for $2,000 \mathrm{mg} / \mathrm{kg}$ ). Additionally, no toxic effects were found in normal mice treated with $2,000 \mathrm{mg} / \mathrm{kg}$ of this extract.

\section{Discussion}

In the current study, we provide evidence that malariaassociated renal injury could be protected against by using the aqueous crude extract of neem leaves in PbANKA infected mouse model. Impairment of renal function during malaria infection has been reported by clinical reports, and it is an important life-threatening complication of malaria infection that goes beyond the classical clinical symptoms of malaria [22, 23]. Moreover, the adversities to access of medical services or delay in diagnosis in their place of origin is implicated in the severity of disease. The onset of renal injury in PbANKA infected mice came out from day 4 


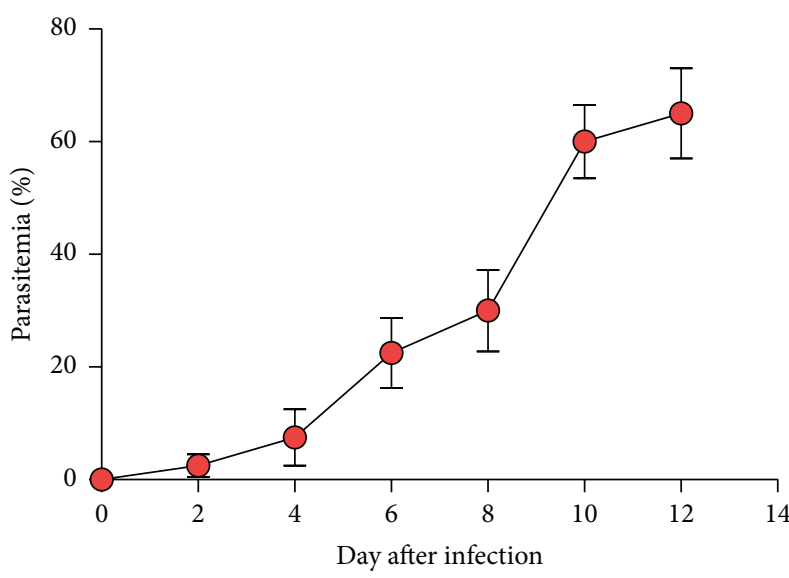

(a)

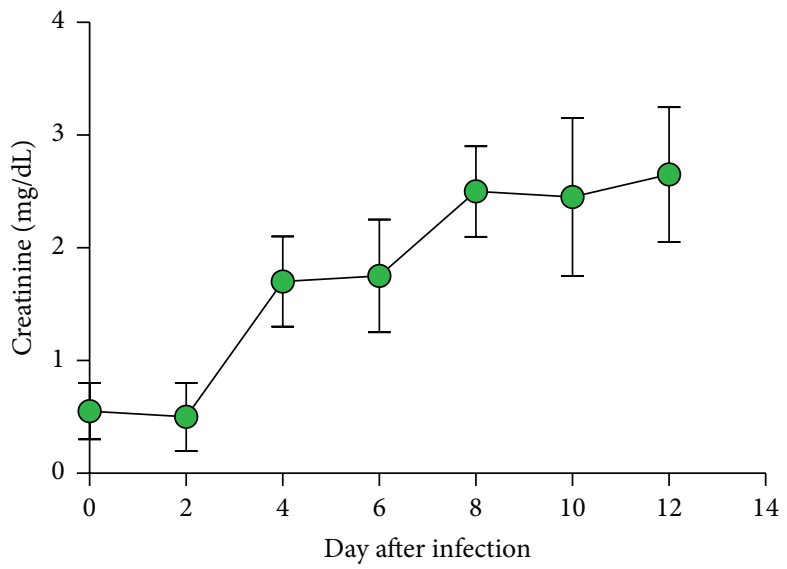

(c)

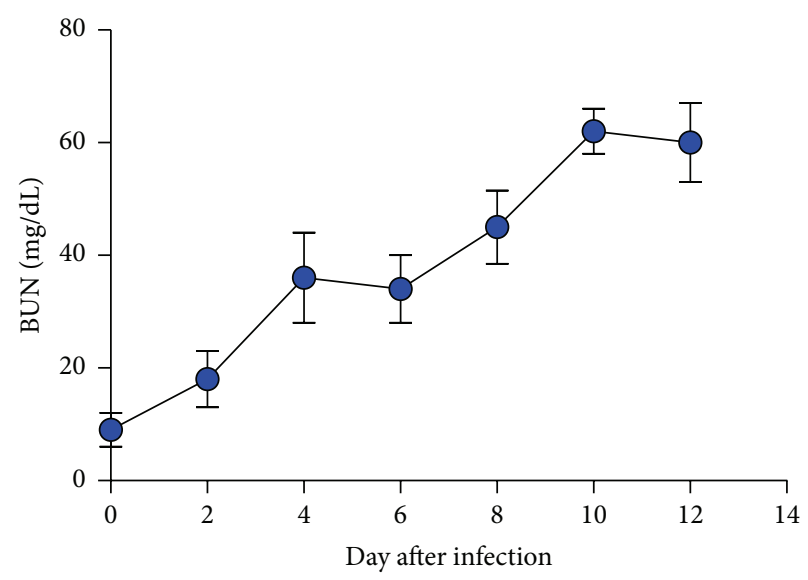

(b)

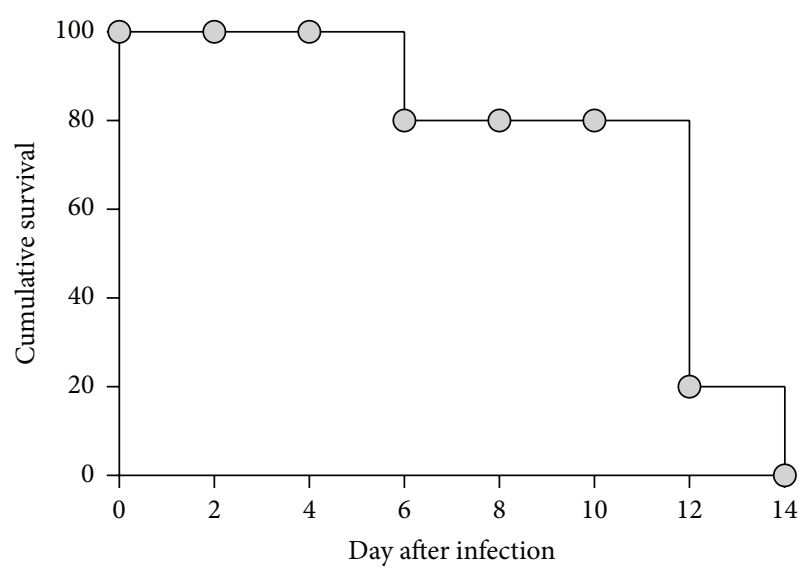

(d)

FIGURE 1: Malaria-associated renal injury induced by Plasmodium berghei infection in mice. Groups of ICR mice ( 5 mice of each) were infected with $1 \times 10^{7}$ parasitized erythrocytes of PbANKA by IP injection. (a) Parasitemia, (b) BUN, and (c) creatinine levels were daily measured. (d) Cumulative survival of infected mice was also observed. Results were expressed as mean \pm SEM.

after infection and the incidence of renal injury was confirmed through manifestation including marked increases of plasma BUN and creatinine levels. It can be suggested that pathophysiology of malaria infection was usually associated with an activation of immune system and comprehends a complex network with production of ROS, oxidative stress, and inflammation [24-28]. It has also been described that the erythrocyte destruction during blood stage of infection accumulated high levels of toxic free heme in circulation that had the ability to induce oxidative stress from production of hydroxyl radicals via the Fenton/Haber-Weiss reaction and resulting renal injury [29-31]. Apoptosis of renal tissues during malaria infection has also been suggested in renal injury [30]. Additionally, pathogenesis of malaria-associated renal injury is most likely to be due to immune-complexmediated glomerulonephritis caused by immune-complex deposition and endothelial damage, which may lead to fatal forms of malarial nephropathies [32].

The present study here has demonstrated that aqueous crude extract of neem leaves significantly reduced plasma BUN and creatinine levels as indicators for renal injury induced by PbANKA infection. This protective effect of neem leaf extract on renal injury may be due to its unique composition, where the leaf extract neem is rich in flavonoids (rutin and quercetin, flavonoglycosides, polyphenols, and tannins) [13]. Flavonoids in neem have been described to possess both antioxidant and anti-inflammatory activities via scavenging free radicals and inhibit lipid peroxidation [33]. Furthermore, neem leaves are rich in polyphenols, which are known for their potent antioxidant and free radical scavenging properties $[9,11]$. Therefore, antioxidant and free radical scavenging activities of neem leaf extract might play a critical role to protect against renal injury induced by $\mathrm{PbANKA}$ infection in mice. In addition, it has been reported that neem leaf extract in both crude extract and active ingredient, azadirachtin, showed the antimalarial property against $\mathrm{PbANKA}$ infected mice and might be due to the effect of this plant to protect against renal injury induced by malaria [34].

\section{Conclusion}

The results obtained in this study showed the aqueous crude extract of neem ( $A$. indica) leaves exerted a dose-dependent 


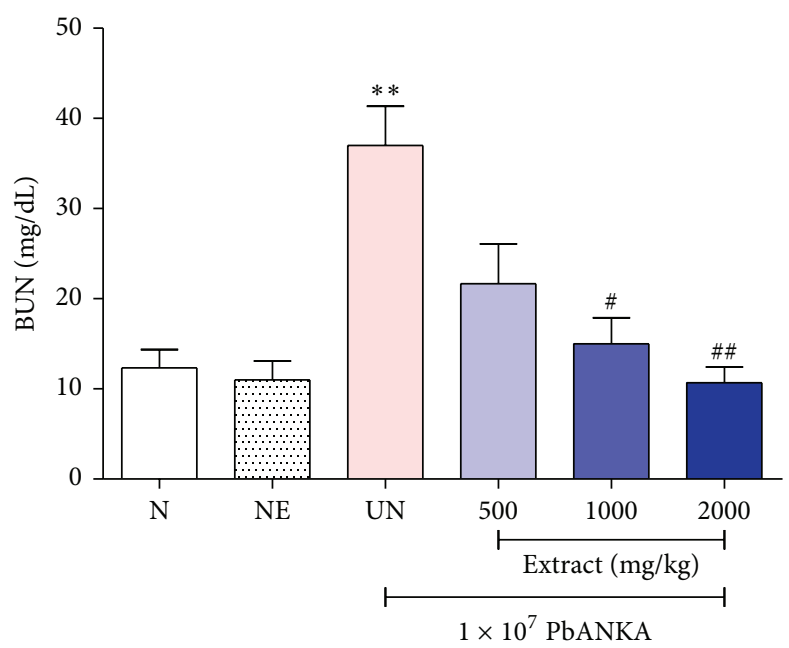

(a)

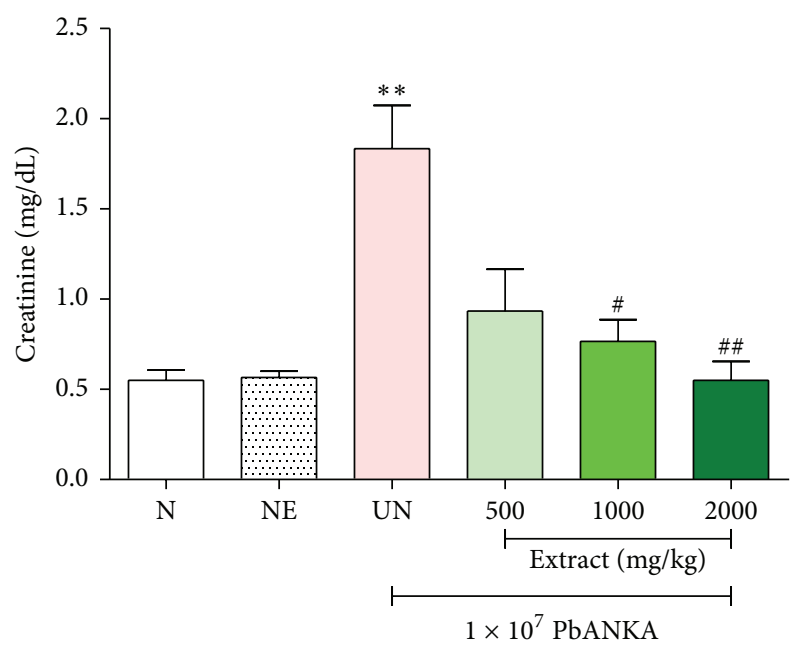

(b)

FIGURE 2: Protective effect of aqueous crude extract of neem leaves on renal injury induced by Plasmodium berghei infection in mice. Groups of ICR mice ( 5 mice of each) were infected with $1 \times 10^{7}$ parasitized erythrocytes of PbANKA by IP injection and given 500, 1,000, and $2,000 \mathrm{mg} / \mathrm{kg}$ of neem leaf extracts orally for 4 consecutive days. On day 5 of experiment, (a) BUN and (b) creatinine levels were measured and compared to normal and untreated groups. Results were expressed as mean \pm SEM. ${ }^{* *} P<0.01$, compared to normal group, ${ }^{*} P<0.05$ and ${ }^{\# \#} P<0.01$, compared to untreated group. N: normal mice, NE: normal mice treated with 2,000 mg/kg of neem leaf extract, and UN: untreated mice.

protective activity of renal damage induced by $P$. berghei. It was most effective at the dose levels of 1,000 and $2,000 \mathrm{mg} / \mathrm{kg}$. This plant can be recommended for use since it possessed a high protective effect against malaria and can be obtained at relatively no cost from nature.

\section{Conflict of Interests}

The authors have declared no conflict of interests regarding the publication of this paper.

\section{Acknowledgments}

The authors thank Dr. Sakaewan Ounjaijean for helpful discussion on plant extraction. The authors also want to acknowledge Dr. Chairat Uthaipibull and Associate Professor Dr. Somdet Srichairatanakool for their contributions and discussions on $P$. berghei infection model and the efficacy test in vivo.

\section{References}

[1] WHO, World Malaria Report 2011, World Health Organization, 2011.

[2] N. J. White, S. Pukrittayakamee, T. T. Hien, M. A. Faiz, O. A. Mokuolu, and A. M. Dondorp, "Malaria," The Lancet, vol. 383, no. 9918, pp. 723-735, 2014.

[3] S. Eiam-Ong, "Malarial nephropathy," Seminars in Nephrology, vol. 23, no. 1, pp. 21-33, 2003.

[4] R. Sinniah, L. Rui-Mei, and A. Kara, "Up-regulation of cytokines in glomerulonephritis associated with murine malaria infection," International Journal of Experimental Pathology, vol. 80, no. 2, pp. 87-95, 1999.
[5] R. S. Barsoum, "Malarial acute renal failure," Journal of the American Society of Nephrology, vol. 11, no. 11, pp. 2147-2154, 2000.

[6] V. Jeney, J. Balla, A. Yachie et al., "Pro-oxidant and cytotoxic effects of circulating heme," Blood, vol. 100, no. 3, pp. 879-887, 2002.

[7] N. Sibmooh, P. Yamanont, S. Krudsood et al., "Increased fluidity and oxidation of malarial lipoproteins: relation with severity and induction of endothelial expression of adhesion molecules," Lipids in Health and Disease, vol. 3, article 15, 2004.

[8] L. D. O. Mora, L. M. G. Antunes, H. D. C. Francescato, and M. D. L. P. Bianchi, "The effects of oral glutamine on cisplatin-induced nephrotoxicity in rats," Pharmacological Research, vol. 47, no. 6, pp. 517-522, 2003.

[9] W. Chaisawangwong and W. Gritsanapan, "Quality assessment and scavenging activity of Siamese neem flower extracty," Natural Product Research, vol. 27, no. 4-5, pp. 394-401, 2013.

[10] P. Sithisarn, R. Supabphol, and W. Gritsanapan, "Comparison of free radical scavenging activity of Siamese neem tree (Azadirachta indica A. Juss var. siamensis Valeton) leaf extracts prepared by different methods of extraction," Medical Principles and Practice, vol. 15, no. 3, pp. 219-222, 2006.

[11] P. Sithisarn, R. Supabphol, and W. Gritsanapan, "Antioxidant activity of Siamese neem tree (VP1209)," Journal of Ethnopharmacology, vol. 99, no. 1, pp. 109-112, 2005.

[12] R. Paul, M. Prasad, and N. K. Sah, "Anticancer biology of Azadirachta indica L (neem): a mini review," Cancer Biology \& Therapy, vol. 12, no. 6, pp. 467-476, 2011.

[13] M. A. Dkhil, S. Al-Quraishy, A. E. Abdel Moneim, and D. Delic, "Protective effect of Azadirachta indica extract against Eimeria papillata-induced coccidiosis," Parasitology Research, vol. 112, no. 1, pp. 101-106, 2013.

[14] R. Subapriya, R. Kumaraguruparan, S. K. Abraham, and S. Nagini, "Protective effects of ethanolic neem leaf extract on 
DMBA-induced genotoxicity and oxidative stress in mice," Journal of Herbal Pharmacotherapy, vol. 5, no. 4, pp. 39-50, 2006.

[15] R. Subapriya, R. Kumaraguruparan, S. K. Abraham, and S. Nagini, "Protective effects of ethanolic neem leaf extract on $\mathrm{N}$-methyl- $\mathrm{N}^{\prime}$-nitro-N-nitrosoguanidine-induced genotoxicity and oxidative stress in mice," Drug and Chemical Toxicology, vol. 27, no. 1, pp. 15-26, 2004.

[16] A. L. Sunarwidhi, S. Sudarsono, and A. E. Nugroho, "Hypoglycemic effect of combination of Azadirachta indica A. Juss. and Gynura procumbens (Lour.) Merr. ethanolic extracts standardized by rutin and quercetin in alloxan-induced hyperglycemic rats," Advanced Pharmaceutical Bulletin, vol. 4, pp. 613-618, 2014.

[17] V. S. Kumar and V. Navaratnam, "Neem (Azadirachta indica): prehistory to contemporary medicinal uses to humankind," Asian Pacific Journal of Tropical Biomedicine, vol. 3, no. 7, pp. 505-514, 2013.

[18] A. Koul, V. Mohan, and S. Bharati, “Azadirachta indica mitigates DMBA-induced hepatotoxicity: a biochemical and radiometric study," Indian Journal of Biochemistry \& Biophysics, vol. 51, no. 1, pp. 37-45, 2014.

[19] T. A. Babu and S. Ananthakrishnan, "Idiopathic intracranial hypertension secondary to ingestion of Morinda coreia and Azadirachta indica leaves extract in infant," Journal of Pharmacology \& Pharmacotherapeutics, vol. 4, no. 4, pp. 298-299, 2013.

[20] A. Oluwole Busayo, Z. Laura, D. Olufunke Olubusola, A. Oluwafunmike Sharon, D. Luciana, and C. M. Ezekiel Ademola, "Ameliorative effects of ethanolic leaf extract of Azadirachta indica on renal histologic alterations in streptozotocin-induced diabetic rats," The American Journal of Chinese Medicine, vol. 39, no. 5, pp. 903-916, 2011.

[21] W. Peters, J. H. Portus, and B. L. Robinson, "The chemotherapy of rodent malaria, XXII. The value of drug resistant strains of Plasmodium berghei in screening for blood schizontocidal activity," Annals of Tropical Medicine and Parasitology, vol. 69, no. 2, pp. 155-171, 1975.

[22] M. Al Rohani, H. Aljawshaei, and E. Aduolimi, "Acute renal failure in Yemeni patients," Saudi Journal of Kidney Diseases and Transplantation, vol. 22, no. 4, pp. 829-833, 2011.

[23] T. William, J. Menon, G. Rajahram et al., "Severe Plasmodium knowlesi malaria in a tertiary care hospital, Sabah, Malaysia," Emerging Infectious Diseases, vol. 17, no. 7, pp. 1248-1255, 2011.

[24] N. Narsaria, C. Mohanty, B. K. Das, S. P. Mishra, and R. Prasad, "Oxidative stress in children with severe malaria," Journal of Tropical Pediatrics, vol. 58, no. 2, pp. 147-150, 2012.

[25] R. Bilgin, M. S. Yalcin, G. Yucebilgic, I. S. Koltas, and S. Yazar, "Oxidative stress in vivax malaria," The Korean Journal of Parasitology, vol. 50, no. 4, pp. 375-377, 2012.

[26] P. Sobolewski, I. Gramaglia, J. A. Frangos, M. Intaglietta, and H. van der Heyde, "Plasmodium berghei resists killing by reactive oxygen species," Infection and Immunity, vol. 73, no. 10, pp. 6704-6710, 2005.

[27] K. Becker, L. Tilley, J. L. Vennerstrom, D. Roberts, S. Rogerson, and H. Ginsburg, "Oxidative stress in malaria parasite-infected erythrocytes: host-parasite interactions," International Journal for Parasitology, vol. 34, no. 2, pp. 163-189, 2004.

[28] A. Pabón, J. Carmona, L. C. Burgos, and S. Blair, "Oxidative stress in patients with non-complicated malaria," Clinical Biochemistry, vol. 36, no. 1, pp. 71-78, 2003.

[29] F. F. Dutra, L. S. Alves, D. Rodrigues et al., "Hemolysisinduced lethality involves inflammasome activation by heme,"
Proceedings of the National Academy of Sciences of the United States of America, vol. 111, no. 39, pp. E4110-E4118, 2014.

[30] R. M. Elias, M. Correa-Costa, C. R. Barreto et al., "Oxidative stress and modification of renal vascular permeability are associated with acute kidney injury during $P$. berghei ANKA infection," PLoS ONE, vol. 7, no. 8, Article ID e44004, 2012.

[31] Z.-W. Zhang, J. Cheng, F. Xu et al., "Red blood cell extrudes nucleus and mitochondria against oxidative stress," IUBMB Life, vol. 63, no. 7, pp. 560-565, 2011.

[32] H. M. Elsheikha and H. A. Sheashaa, "Epidemiology, pathophysiology, management and outcome of renal dysfunction associated with plasmodia infection," Parasitology Research, vol. 101, no. 5, pp. 1183-1190, 2007.

[33] W. Kitdamrongtham, K. Ishii, K. Ebina et al., "Limonoids and flavonoids from the flowers of Azadirachta indica var. siamensis, and their melanogenesis-inhibitory and cytotoxic activities," Chemistry \& Biodiversity, vol. 11, no. 1, pp. 73-84, 2014.

[34] L. Lucantoni, R. S. Yerbanga, G. Lupidi, L. Pasqualini, F. Esposito, and A. Habluetzel, "Transmission blocking activity of a standardized neem (Azadirachta indica) seed extract on the rodent malaria parasite Plasmodium berghei in its vector Anopheles stephensi," Malaria Journal, vol. 9, article 66, 2010. 


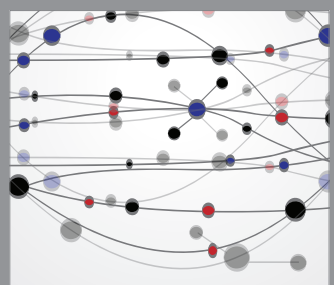

The Scientific World Journal
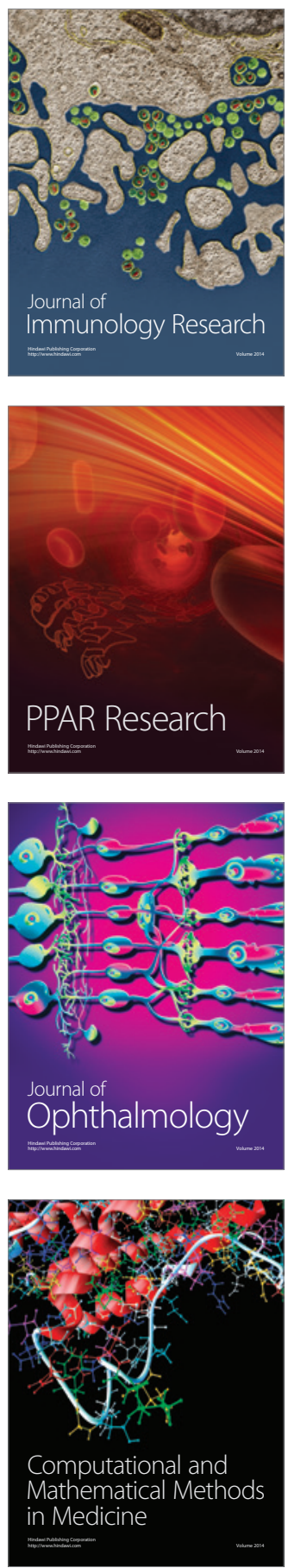

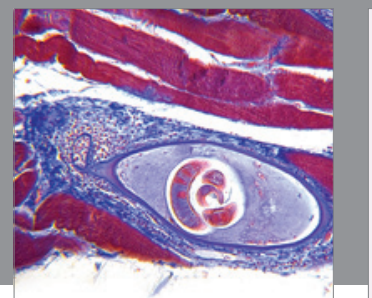

Gastroenterology

Research and Practice
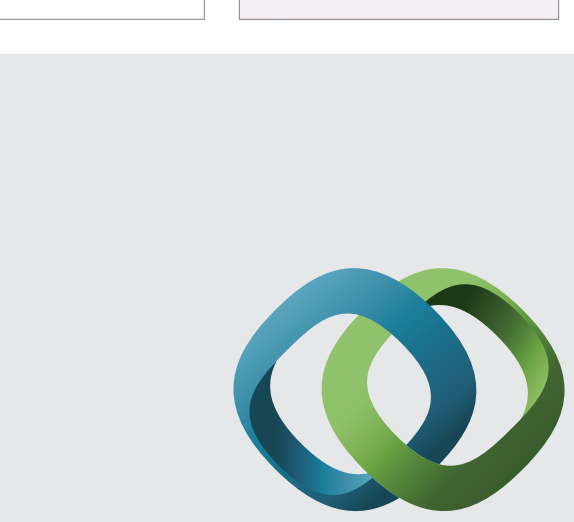

\section{Hindawi}

Submit your manuscripts at

http://www.hindawi.com
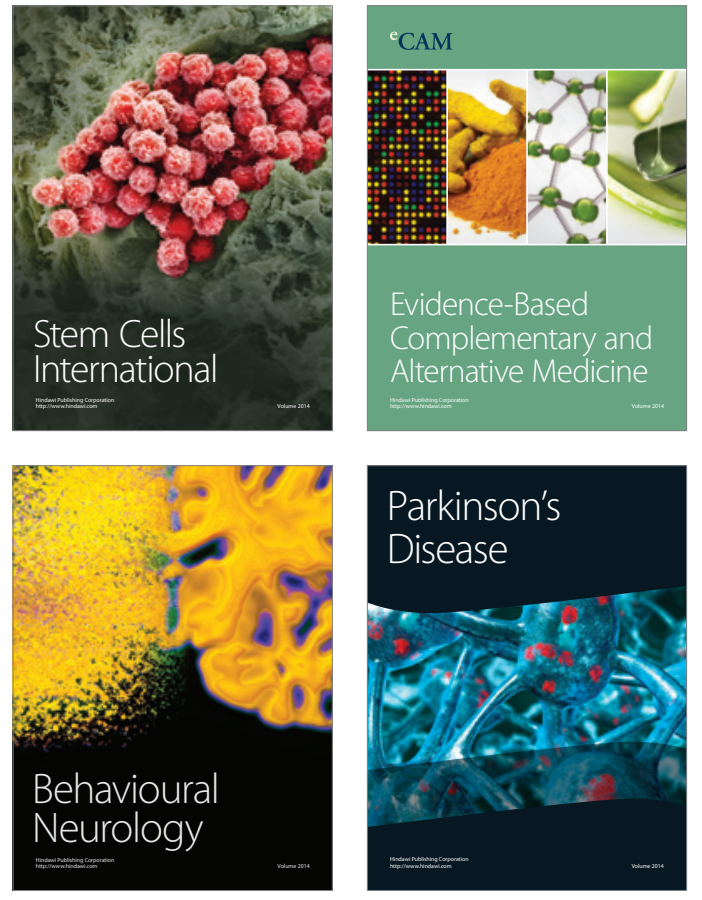
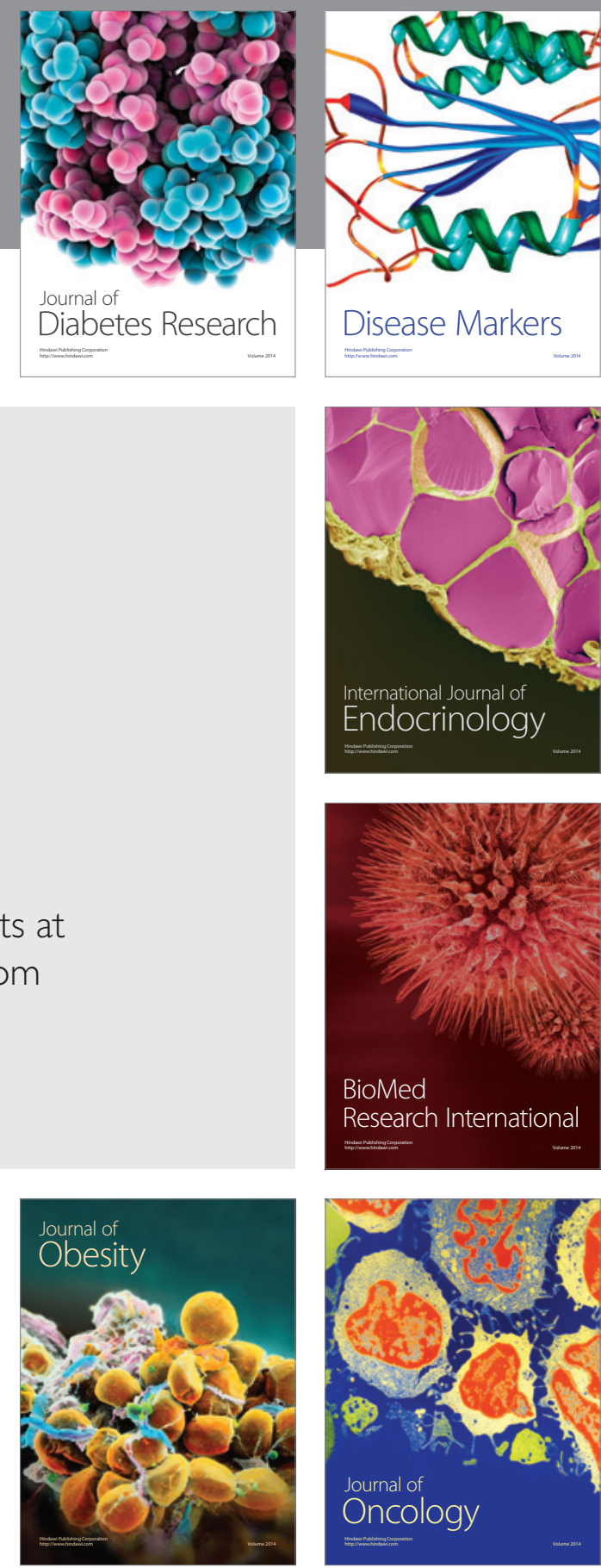

Disease Markers
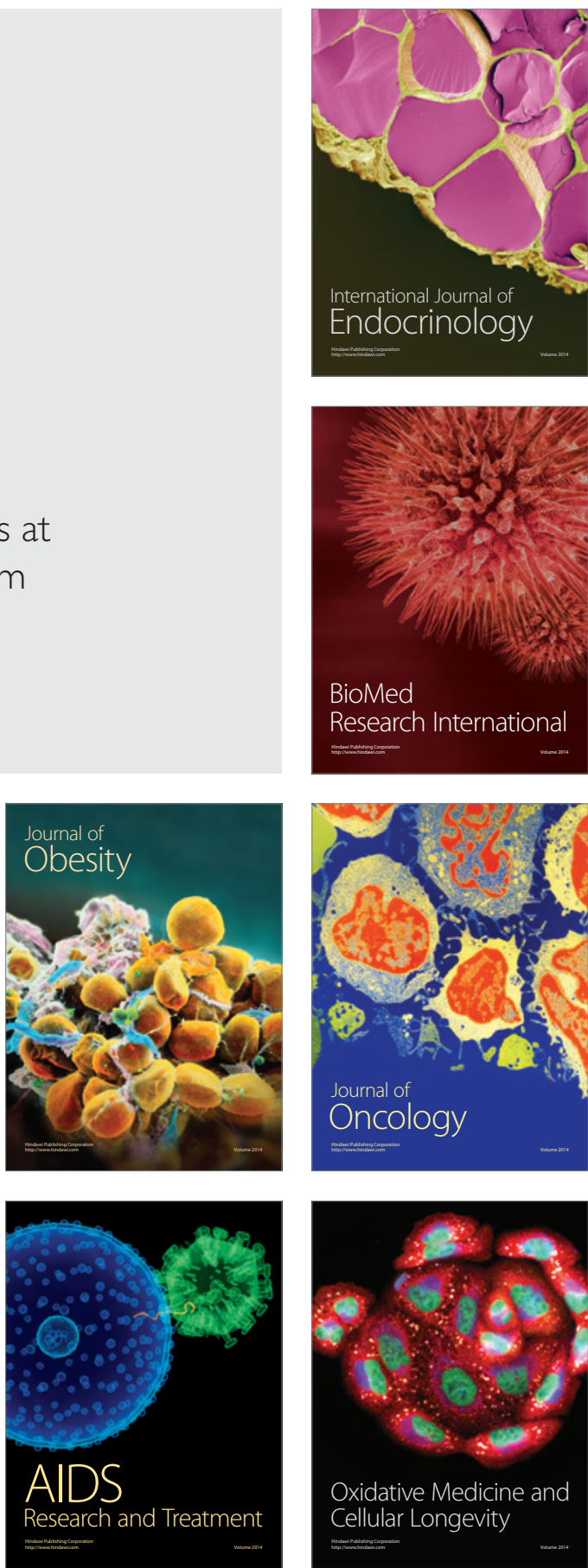